\title{
Experimental Study on the Decompression Performance of the Annular Tube Device Using for the Water Supply System
}

\author{
Dong-ming $\mathrm{HU}^{\mathrm{a}}$, Jie ZHOU ${ }^{\mathrm{b}}$, Cheng-jun $\mathrm{LI}^{\mathrm{c}}$, Ying SONG ${ }^{\mathrm{d}}$, \\ Yong-feng XIE ${ }^{\mathrm{e}}$, JI ZHAO ${ }^{f}$ and ZHOU-song $\mathrm{ZHAO}^{g}$ \\ PowerChina Huadong Engineering Corporation Limited, Hangzhou, Zhejiang, 311122, China \\ ahu_dm@ecidi.com, ${ }^{\text {b}}$ zhou_j@ecidi.com, ${ }^{\mathrm{c} l i \_c j @ e c i d i . c o m, ~}{ }^{\mathrm{d}}$ song_y3@ecidi.com, \\ exie_yf@ecidi.com, zhao_j3@ecidi.com, ${ }^{\mathrm{g}} \mathrm{zhao} z \mathrm{~s} @$ ecidi.com
}

Keywords: Decompression performance. Annular tube. Pressure. Experimental system. Working condition.

Abstract. To solve the disadvantages of pressure relief devices in water supply system such as pressure relief valve and throttle orifice plate for high fault rate and high operation costs, the new type of the annular tube device was proposed, which has the advantages of simple structure, high reliability and low cost. The working principle of the device was described. And the experimental system was established. The decompression performance was obtained under different downstream pressure and flow working conditions. The test results show that decompression performance of the annular tube device was excellent and correct, which is of great value practically.

\section{Introduction}

In the hydropower station, the water supply system often uses self-reduced pressure water supply when the water supply pressure is much higher than the user required. At present, the common pressure-relief devices include the reducing valve and the throttle orifice plate. The reducing valve is expensive and has the shortcomings of the high fault rate [1], which increases the plant maintenance cost, and also brings adverse effect on the safety and stability of the power plant unit. Meanwhile, a large number of applied results also showed that the throttle orifice plate pressure-relief devices had the disadvantages of the easily blocked, noise, and easy erosion in downstream piping [2].

The annular tube is a new type of pressure-relief devices applied in the water hydraulic system. Compared to the reducing valve or throttle orifice plate devices, it has advantages of low cost, high reliability, and low maintenance costs, which is suitable for water conservancy and hydropower engineering, building water supply system, fire control system or drinking water system. In this paper, the working principle of the annular tube device is introduced, the test system is set up, and the the accuracy of the design for annular tube is verified by experiments.

\section{Structure design of the annular tube}

\section{Design consideration}

For the theory of fluid mechanics, the head loss in water supply system has two types [3]: frictional head loss and local head loss. In the general water pipe, the frictional head loss is the majority, its formula is as follows:

$$
h_{f}=\lambda \frac{L}{d} \frac{v^{2}}{2 g}
$$

Where $\lambda$ is the coefficient of friction resistance, $L$ and $d$ are the length and diameter of pipe respectively, $v$ is the water flow velocity in pipe, $g$ is the acceleration of gravity.

The coefficient of frictional resistance $\lambda$ is related with water flow conditions, its value may be referred by the experience formula or icon, such as Moody figure, hydraulic friction empirical formula under different water flow conditions [4]. 
From the formula (1), we can know that the frictional head loss is proportion to the tube length, and in inverse proportion to the diameter when the flow rate and friction coefficient are known, which is the design basis for the annular tube device.

\section{The application under different flow rate and pressure drop}

In the water supply piping system, to achieve the rapid decompression, the annular tube should be designed with long length based on the design basis of formula (1). And it must be set in a limited range in the system. As a result, the designed annular tube is the type of circular spiral structure or rounded rectangle spiral structure, which is shown in figure 1.

As using annular tube in the water supply system, the working conditions are different. When the water flow rate is larger, two or more monomers can be used with parallel connection, and each annular tube has the same size and number of turns, to make the flow double or more times under the same stress effect [5].
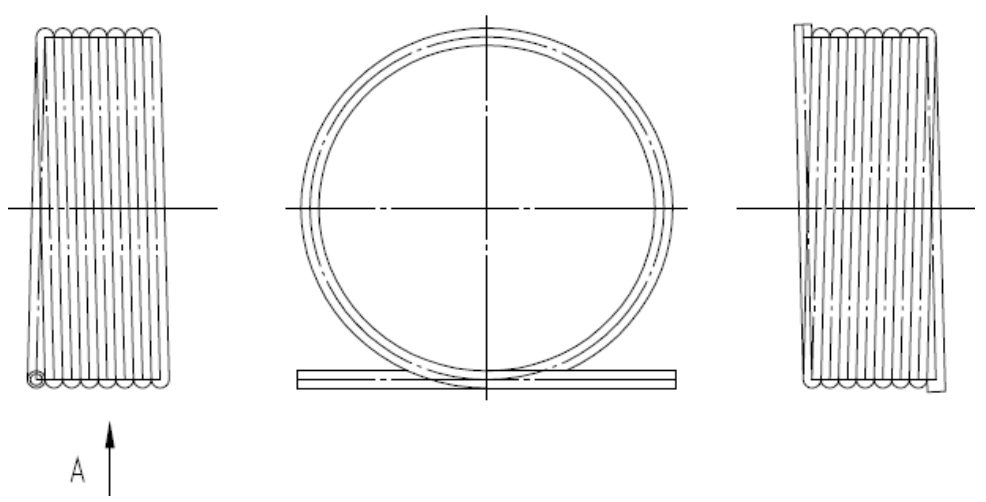

Fig. 1, The schematic diagram of the annular tube

On the other hand, in order to increase the reduced pressure effect under the same flow, two or more of the same type annular tube can be connected in series, so that the pressure effect is increased by double or multiple times [5].

\section{The experiment system}

The experimental system was established in order to test the decompression effect of the annular tube device. The system is mainly composed of the electric motor, the water pump, the water tank, the throttle valve, the gate valve, pipes and accessories, annular tube, measuring instrument (including flow meter, pressure transducer, liquid level meter, and thermometer), electric control cabinet, monitoring and other components. The data acquisition system and the layout diagram of test equipment were shown in figure 2 and figure 3.

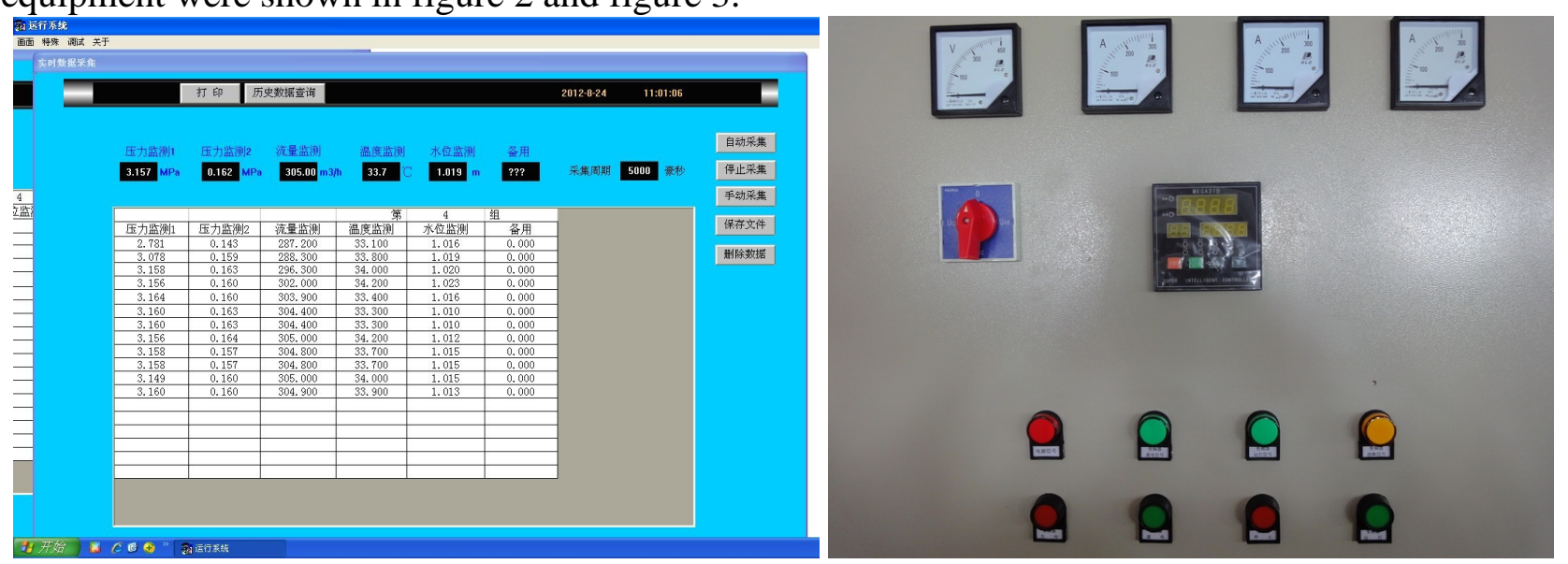

Fig. 2, The interface of data acquisition system 

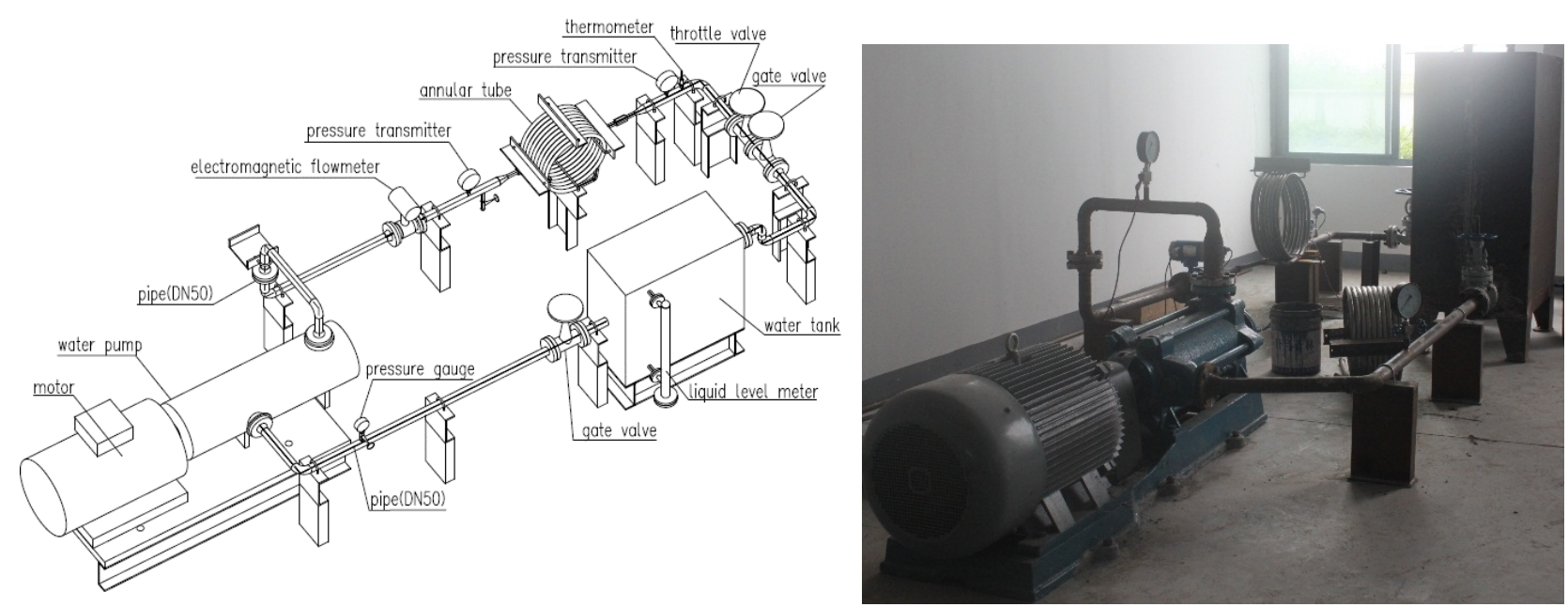

Fig. 3, The layout of the test rig

The test annular tube was installed between the export of water pump and the throttle valve. And the downstream water pressure can simulated by setting the opening size of the throttle valve. The water flow can be controlled by setting the frequency of the inverter, which can get different speed of motor and pump. And for any two points on the same flow line, the formula of Bernoulli equation [6] is:

$$
z_{1}+\frac{p_{1}}{\rho g}+\frac{u_{1}^{2}}{2 g}=z_{2}+\frac{p_{2}}{\rho g}+\frac{u_{2}^{2}}{2 g}+h_{1-2}
$$

Where $z_{1}$ and $z_{2}$ are the water elevations of the flow in the front point and back point of annular tube respectively, $p_{1}$ and $p_{2}$ are the water pressures in the two flow points respectively, $u_{1}$ and $u_{2}$ are flow velocity respectively, $h_{1-2}$ is the head loss, or pressure drop between the two flow points.

In the test, two pressure points have the same elevation as well as the diameter and flow velocity. Therefore the pressure difference of the two points front and back is the head loss.

\section{Performance analysis}

In order to verify the effectiveness of the design for annular tube, the theoretical results calculated by formula (1) and the test results were compared, which were shown in figure 4. 


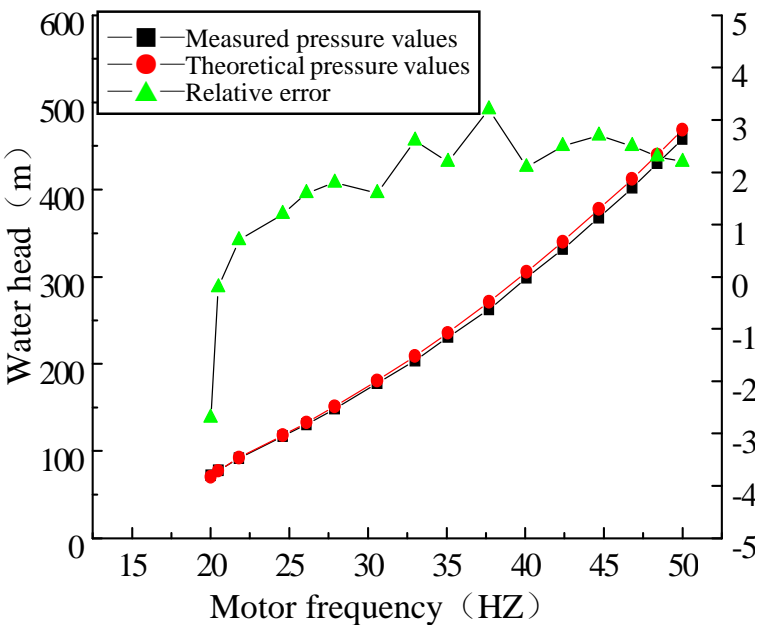

(a) Throttle valve opening 0.03

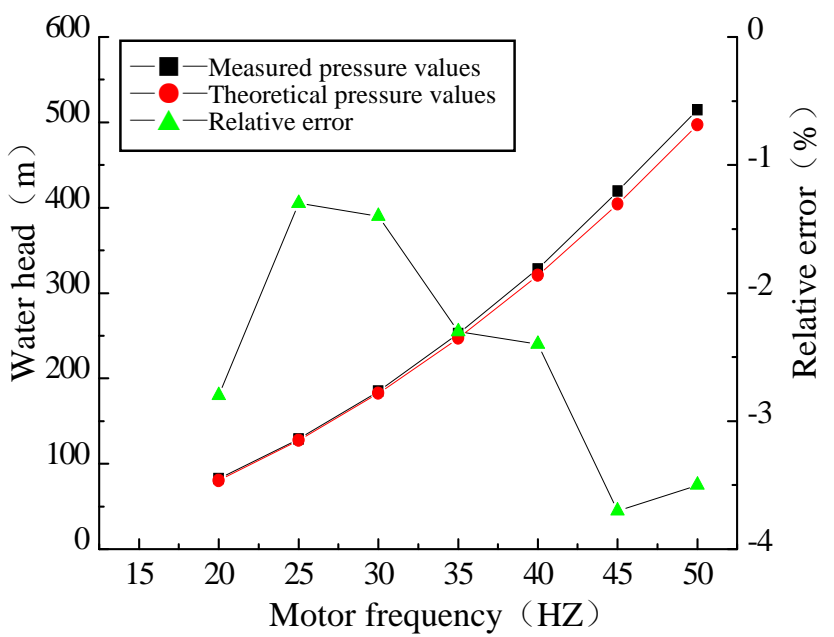

(c) Throttle valve opening 0.3

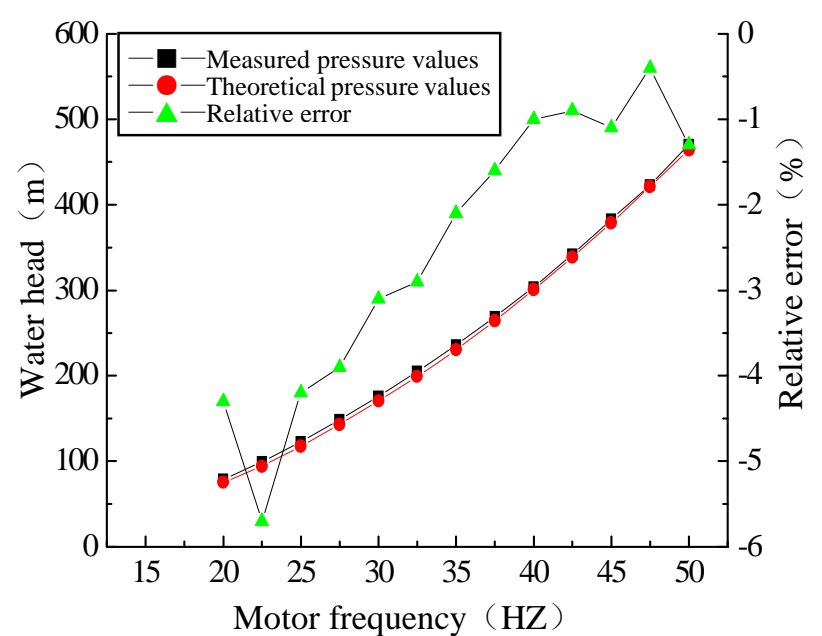

(b) Throttle valve opening 0.1

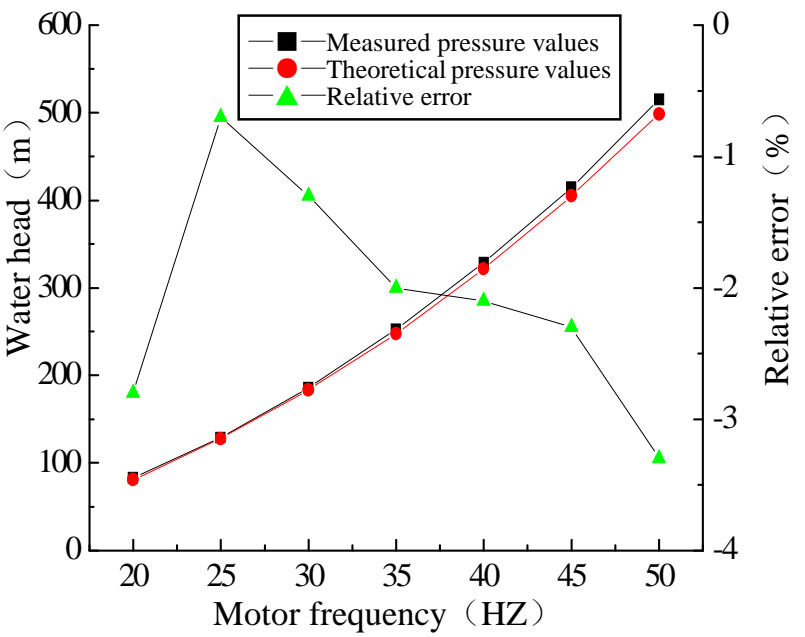

(d) Throttle valve opening 0.5

Fig. 4, The decompression performance test with annular tube

The pressure of the annular tube downstream would change because of the difference opening of throttle valve. The smaller throttle valve opening, the more obvious change of the pressure in downstream measuring point exist. Therefore in the test, the data acquisition point was relatively adequate. On the other hand, the larger throttle valve opening, the downstream pressure was more close to zero-pressure in the water tank. The pressure did not change much with the flow varying. Therefore, the data in figure $4 \mathrm{c}$ and figure $4 \mathrm{~d}$ were less than those in figure $4 \mathrm{a}$ and figure $4 \mathrm{~b}$.

As you can see from figure 4 , the measured values and the theoretical calculation values are consistent under the working conditions of different throttle opening and motor frequency, which show that the annular tube design basis is accurate and effective. In addition, when the throttle opening was smaller, the relative error of the measured value and the calculated value was larger. The largest one was about $5.6 \%$ (in figure $4 \mathrm{~b}$, throttle opening 0.1 , motor frequency $22.5 \mathrm{HZ}$ ). And when the throttle opening was larger, as shown in figure $4 \mathrm{c}$ and figure $4 \mathrm{~d}$, the relative error of the measured value and the calculated value was smaller. The test results showed that the relative error between the measured stress value and theoretical calculation value was in the range of $-6 \% \sim 3 \%$.

In the experiment, we also found that the annular tube had some vibration and noise when the system flow was relatively large in the test. Except that, it did not appear other phenomenon similar to the throttling orifice plate such as easy congestion, big noise etc., which was mainly due to the advantages of its ring structure. 


\section{Conclusions}

The annular tube is a new type of pressure relief devices used in the water supply system, and compared it with the past commonly used devices, such as pressure relief valve and throttle orifice plate, it had the advantages of simple structure, high reliability, low cost.

A large number of testing results showed that the measured and the theoretical calculation decompression values of the annular tube were consistent under different working conditions, which demonstrates that annular tube design principle is accurate and effective indeed.

\section{Acknowledgements}

This work was financially supported by the project of Pumped Storage Engineering Center of Zhejiang Province.

\section{References}

[1] W. Y. JIANG: Summary on Application of ten years for Water Pressure Reducing Valve. Water \& Wastewater Engineer, Vol. 26-2 (2000), p. 51

[2] J. JIANG: Discussion on the selection and installation of the pressure reducing valve for water supply system. Public Engineering Design, Vol. 5-7 (2009), p. 74

[3] H. J. ZHANG and Y.HUANG: Hydraulic transmission, published by the China Machine Press, Beijing, China (2001)

[4] T. W.YI: Study on Overpressure and Pressure-relief on Fire Water Supply System in High-rise Building, [D]. Xi'an University of Architecture and Technology, China (2008)

[5] LI. C. J, ZHOU. J and YAN. L, China Patent CN 201513667 U. (2010)

[6] E. X. YUN: Engineering Fluid Mechanics, published by the Petroleum Industry Press, Beijing, China (2000) 